\title{
The Impact of Healthy Lifestyle Multimedia Education on Elderly Life
}

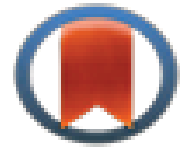

CrossMark

dick for updates

\section{Promotion}

\author{
Movahedi $\mathrm{M}^{1}$, *Khamseh $\mathrm{F}^{2}$, Ebadi A ${ }^{3}$, Haji Amini $\mathrm{Z}^{4}$
}

1- Instructor, Behavioral Sciences Research Center, Faculty of Nursing, Baqiyatallah University of Medical Sciences. (AJ), Tehran, Iran.

2- Instructor, Behavioral Sciences Research Center, Faculty of Nursing, Baqiyatallah University of Medical Sciences, Tehran, Iran (Corresponding Author)

E.mail: khamseh_110@yahoo.com.

3- Professor, Institute of Behavioral Sciences Research Institute of Lifestyle, Faculty of Nursing, Baqiyatallah University of Medical Sciences. Tehran Iran.

4- Assistant Professor, Department of Health, Faculty of Nursing, Baqiyatallah University of Medical Sciences, Tehran, Iran.

\section{Abstract}

Introduction: Elderly health is one of the most important health issues in most societies that can be prevented by elderly problems through health care education. The purpose of this study was to determine the effect of multimedia education on promoting healthy lifestyle of the elderly in Tehran.

Method: This clinical trial study was performed on two groups of thirty elderly people with mean age (63.41 6 6.88) who were members of the elderly focal points of Tehran neighborhoods with moderate to poor lifestyle scores. Intervention group received healthy lifestyle training in old age using multimedia educational software and the control group did not receive any intervention. Three months later, the lifestyle of the two intervention and control groups was again assessed.

Results: There was a statistically significant difference between the two groups in the two groups after the intervention $(\mathrm{P}<0.001)$.

Conclusion: Lifestyle education using multimedia educational content is effective in the elderly and due to the importance of healthy lifestyle in preventing the problems of old age and due to the limitations of the elderly for attending healthy lifestyle training classes, The above method can improve the health of the elderly.

Keywords: Multimedia education, Elderly, Healthy lifestyle.

Received: 11 August 2019

Accepted: 22 September 2019

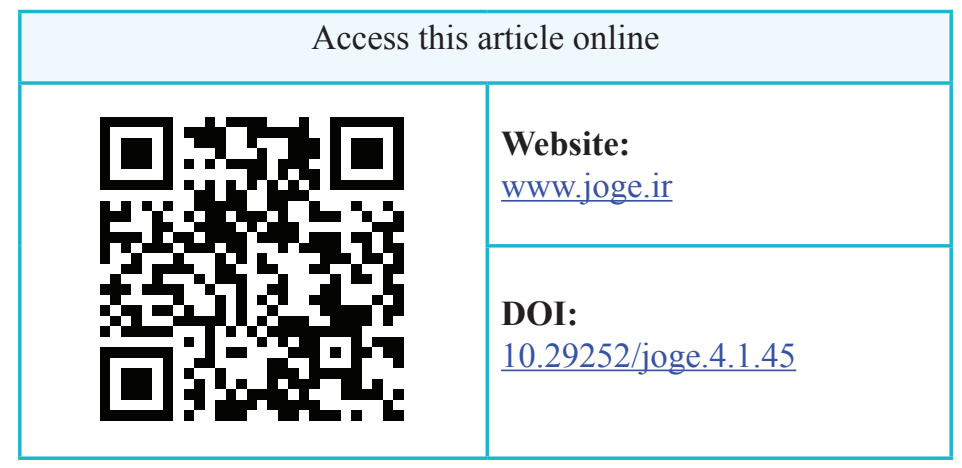




\section{تاثير آموزش حند رسانه اى سبك زندَى سالم بر ارتقاء سبك زندَى سالمندان

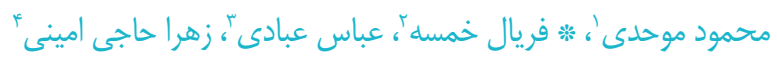

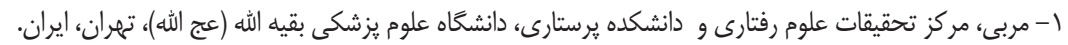

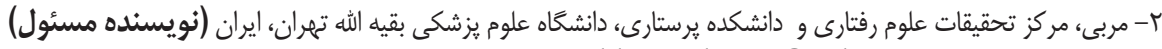
يست الكترونيكى: khamseh_11.@yahoo.com

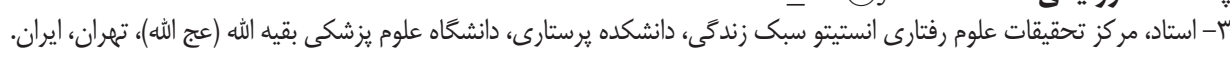

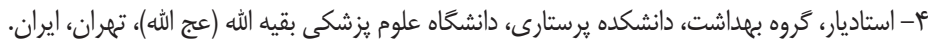

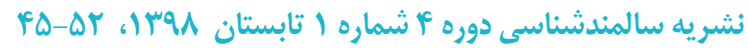

\section{ج)}

مقدمه: سلامت سالمندان يكى از مسائل بهداشتى مهم در اكثر جوامع است كه مى توان با آموزش مراقبت هاى بهداشتى از بروز

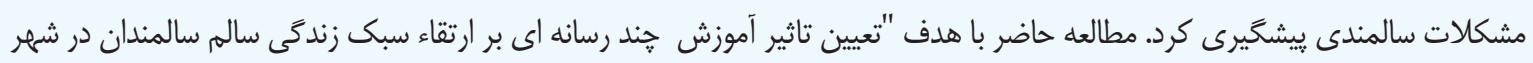
تهران " انجام شد.

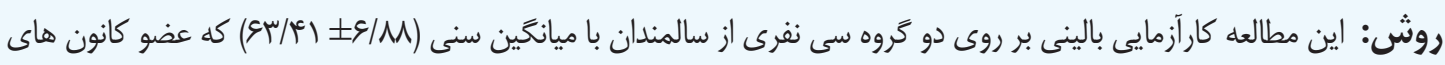

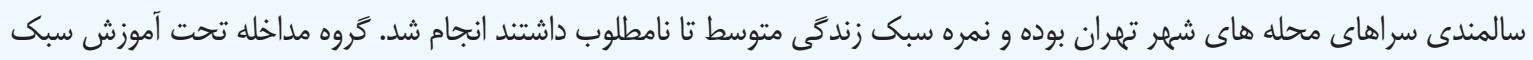

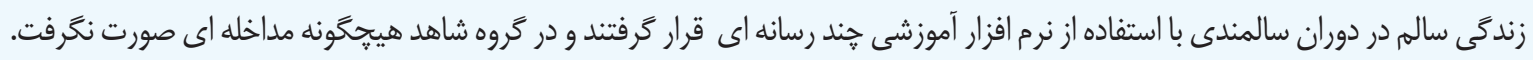

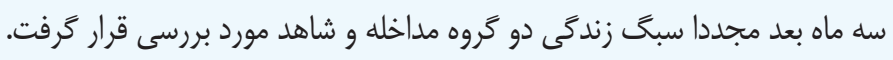

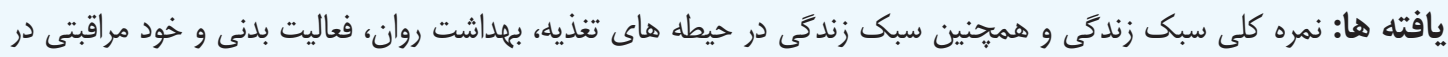

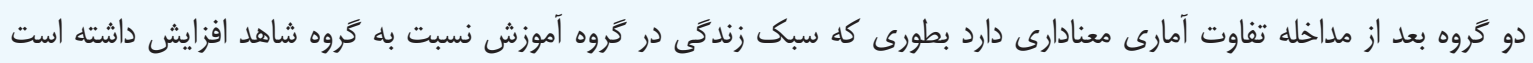
$\cdot(\mathrm{p}<\bullet / \cdots)$

نتيجه كَيرى: آموزش سبك زندكى با استفاده از محتواى آموزشى جند رسانه اى در سالمندان تاثيرگذار بوده و با توجه به اهميت

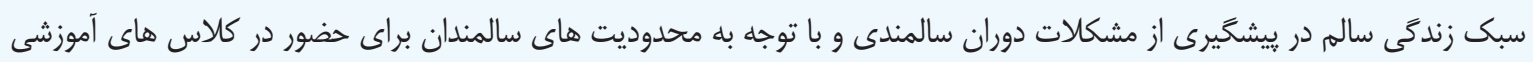
سبك زندگى سالم، استفاده از روش فوق مى تواند ارتقا سلامت سالمندان را محقق نمايد.

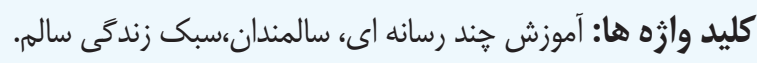

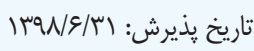

تاريخ دريافت: • •

زندگى ناسالم، سلامت جسمى و روانى سالمندان بيشتر از گذشته در خطر مى باشد. رفتارهاى ارتقادهنده سلامتى يكى از معيارهاى عمده تعيين كننده سلامت است و به طور مستقيم با ييشگيرى از بيماريها در ارتباط مى باشد (أ). بر اساس تحقيقات سازمان جهانى بهداشت نزديك به •و درصد كيفيت زندگى و سلامت افراد به سبك زندگى و رفتار شخصى آنان بستخى دارد (و،ه) مناسب ترين شيوه براى كاهش مشكاتلات مربوط به سالمندى و حركت درجهت سالمندى موفق اتخاذ سبك زندگى سالم در اين دوران مى باشد (V). شواهد نشان مى دهد كه در صورتى كه فرد به طور معمول و به نحو صحيح فعاليت هاى ارتقادهنده سلامتى را انجام دهد، شيوه زندگى بهترى خواهد داشت

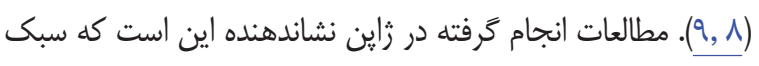

\section{مقالهمه}

با افزايش شهرنشينى، گذر جمعيتى به سوى ميانسالى و سالمندى، و افزايش بار بيمارى هاى غير واگير و مزمن، نكته مهمه، سالم يير شدن و ييشخيرى از اين بيمارى ها است كه علاوه بر مشكلات سلامت، هزينه سنگينى را نيز به بخش سلامت و جامعه تحميل مى كند (l). با توجه به افزايش سريع جمعيت سالمندان، تامين سلامت و رفاه آنان در جامعه هر روز ابعاد گستردهترى ييدا ميكند (با).كاهش تحرك، افزايش شيوع بيمارى هاى جسمى و روانى، مراقبت ناكافى، درآمد كم، ايزوله اجتماعى سبب احساس تنهايى و افسردگى سالمندان مى گردد و احتمال انجام رفتارهاى ارتقادهنده

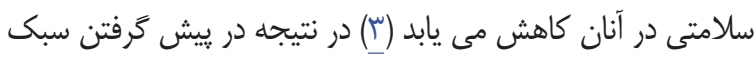


دشوار به نظر مى آيد (·r)، و همجِنين ضرورى بودن ايجاد تغييرات

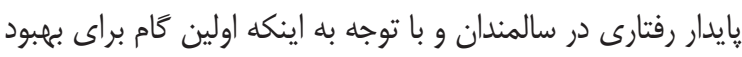
زندكَى در دوران سالمندى دادن اطلاعات و آكاهى، تغيير افكار و

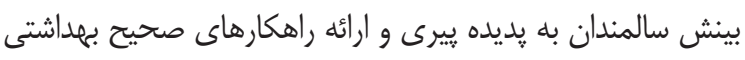

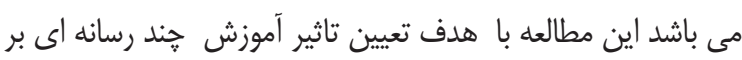
ارتقاء سبك زندگى سالم سالمندان در شهر تهران انجام شد.

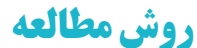

يزوهش حاضر، يك كارآزمايى بالينى دو كروهه با استفاده از

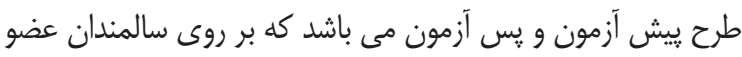
كانون هاى سالمندى در سراهاى محله شهر تهران انجام شد. كانون هاى سالمندى، انجمن هايى محلى هستند كه زير نظر خانه هاى سلامت محله ها تشكيل و اداره مى شوند و خانه هاى سلامت محله ها، خود، زيرمجموعئ ادارٔه سلامت شهردارى تهران هستند. افراد هر سران محله كه هQ سال و بيشتر سن داشته باشند (آ(r)، مى توانند در اين كانون ها ثبت نام كرده و از خدمات آموزشى و تفريحى آنها استفاده كنن. براى انجام اين مطالعه ابتدا در يك مطالعه اي توصيفى تحت

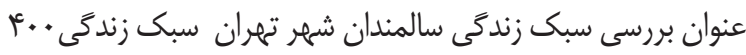

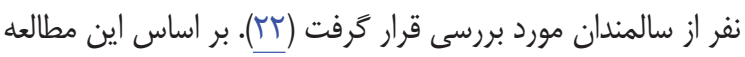
اوليه از ميان افرادى كه داراى سبى زندَّى متوسط يا نامطلوب

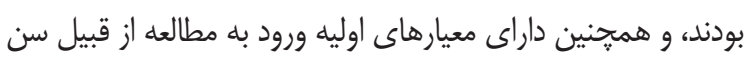
بالاى هه سال، عضويت در كانون هاى سالمندى خانه هاى سلامت،

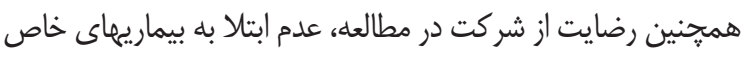

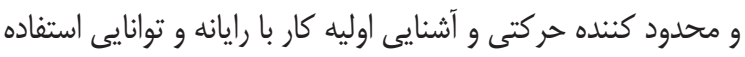
از رايانه با كمك يكى از اعضاى خانواده بودند انتخاب شدند. جهت التهائ انجام مداخله براى دو كروه آزمون و شاهد حجم نمونه مورد نياز در

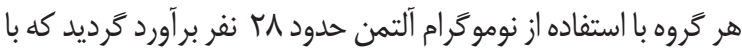
احتمال ريزش • ٪\%، حجم نمونه ·ب نفر محاسبه شد. بنابراين تعداد

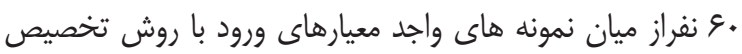

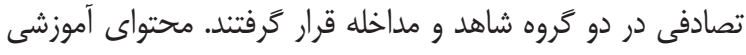
קند رسانه اى با مطالعات گسترده كتابخانه اى و استفاده ازمنابع و متون معتبر و همجنين بهرمندى از نظر متخصصين توسط محققين تدوين شد. بدين صورت كه نظرهاى گروه متخصصين و خبر كان با استفاده از تكنيك دلفى در طى سه راند بصورت وب محور (يست

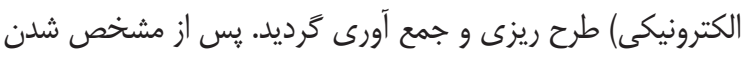

زندگى سالم سبب ييشحيرى از افسردگى در سنين سالمندى مى شود

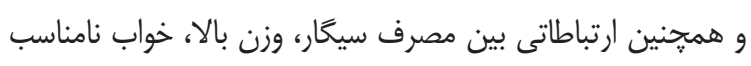
و افزايش ريسك افسردگى و كاهش حافظه نيز بيدا شد (1) (1-.1).

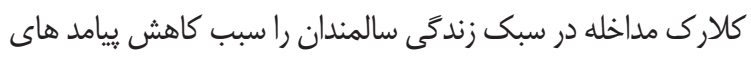
منفى اين دوران دانسته و مداخله در سبك زندگى را داراى اثرات

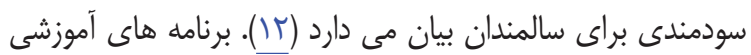
بر رفتارهاى ارتقاء دهنده سلامتى در سالمندان مؤثر مى باشد كه

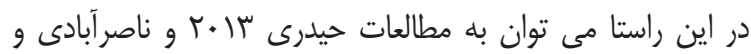

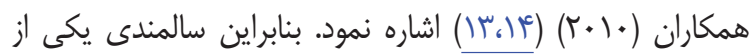
مراحل اجتناب نايذير زندگى است كه مى توان از طريق مداخلات

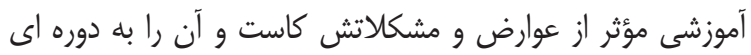
مطلوب و لذت بخش تبديل كرد. از طرفى از آنجايى كه بسيارى از مشكلات دوران سالمندى ناشى از شيوه زندگى ناسالم در اين دوران

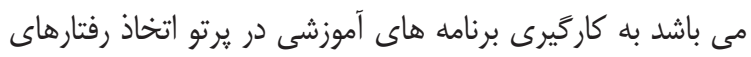
ارتقادهنده سبك زندگى سالم سبب ييشكيرى و كاهش مشكلات

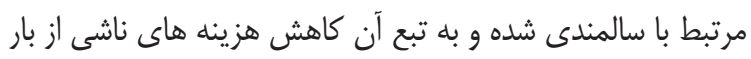
بيمارى در اين دوران مى شود. اين موضوع به خصوص از ديدكاه سياست كذاران و برنامه ريزان نظام سلامت حايز اهميت است

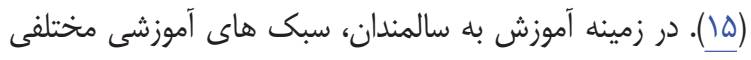

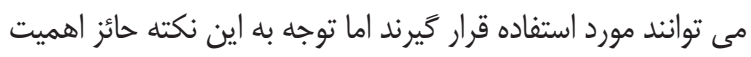
است كه سالمندان ممكن است يذيراى تمامى روشهاى تدريس

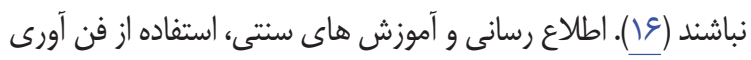

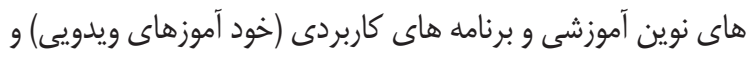

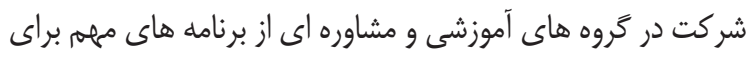

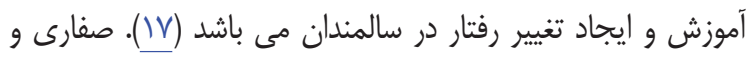
همكاران نيز سخنر انى و نمايش فيلم را به عنوان روش هاى مؤثرى براى ارتقاى سطح آكاهى و نكَرش افراد بزركّال بيان نموده اند

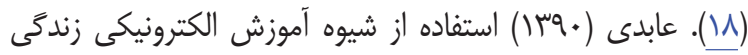

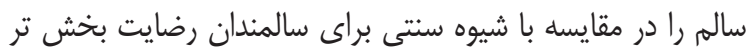
و داراى هزينه كمتر دانسته است (19). افزايش روز افزون جمعيت سلان

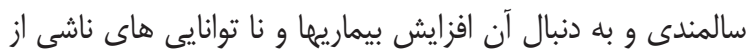

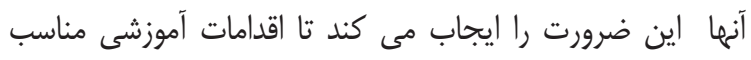

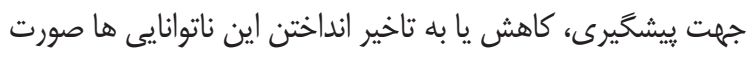

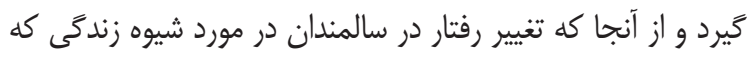

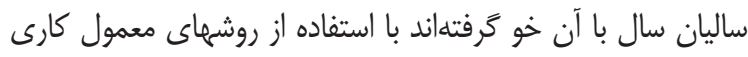


سرگرمى، أl سؤال در حيطه تغذيه سالم، ه سؤال در حيطه مديريت تنش و در نهايت و سؤال در حيطه روابط اجتماعى و بين فردى است

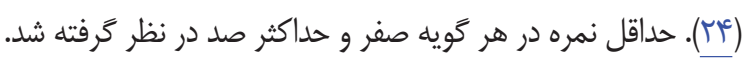
در نهايت، امتياز كلى يرسش نامه محاسبه و در سه سطح مطلوب

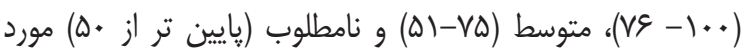
ارزيابى قرار گرفت. تجزيه و تحليل اطلاعات با استفاده از نرم افزار

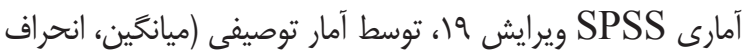
معيار) و همجنين آمار استنباطى (آزمون هاى تى زوجى جهت مقايسه ميانگين قبل و بعد از مداخله در هر دو گروه، و تى مستقل جهت مقايسه ميانخين ها در دو گروه صورت كرفت. در ضمن يس از انجام تست مرحله دوم بمنظور رعايت اصول اخلاقى محتواى آموزش بصورت نرم افزار در اختيار گروه شاهد نيز قرار گرفت و نحوه كار با آن نيز براى اين گروه آموزش داده شد.

\section{1.}

ميانگَين سنى گروه هاى مداخله بازده (ه - - DQ سال) بود مشخصات جمعيت شناختى دو گروه در (جدول () ارائه شده است. يافته ها نشان مى دهند كه دو گروه در متغيرهاى دموگر افيك همگَن بودند. نمره سبك زندگَى در كل و در جهار حيطه (تغذيه، مراقبت از خود، بهداشت روان و فعاليت بدنى)، در دو گروه بعد از مداخله تفاوت آمارى معنادارى داشت (1 + • (p). همجنين ميانخين تغييرات نمرات قبل و بعد از مداخله در گروه آزمون تفاوت معنادارى داشت و اختلاف ميانگين نمرات بيانگر اين بود كه آموزش جند رسانه اي هم در نمره كل و هم در نمره ساير حيطه ها

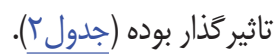

حيطه ها و عناوين آموزشى بر اساس ميزان اهميت و ميزان زمان مورد نياز جهت هر مبحث، محتواى آموزشى شامل متن، عكس، مئ فيلهم و صوت از منابع مختلف جمع آورى و طبق فرمت SCORM

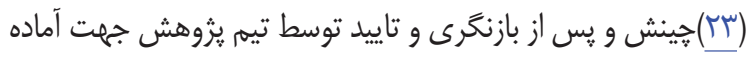
سازى به متخصص طراح نرم افزار خند رسانه اى داده شد. پِ از

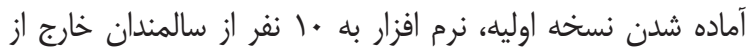
مطالعه ارائه و از آنها خواسته شد كه نظرات خود را در خصوص نكات اصلى در رسانه ارائه شده و بخش هاى مبهم و نامفهوم بيان نمايند و پِ از جمع بندى اين نظرات، نرم افزار مورد نظر جهت ويرايش

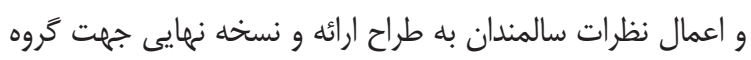
أزمون تهيه گَرديد. محتواى آموزشى گֶند رسانه اى بصورت يك نرم افزار آموزشى در اختيار گروه آزمون قرار گرفت و محقق در باره

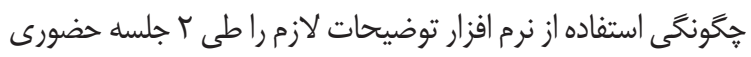
ارائه نموده و با در اختيار قرار دادن شماره تماس به افراد و گرفتن شماره تماس آنها، از طريق ييگير ى هاى تلفنى مسائل و مشكلات

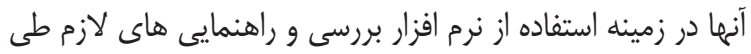

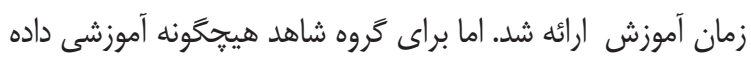
نشد. بعد از كذشت يك دوره س ماهه جهت سنجش تاثير آموزش جند رسانه اى بر سبك زندگى سالمندان مجددا يرسشنامه سبك زندگى به گروه هاى آزمون و شاهد داده شد و سبك زندگى دو گروه مورد ارزيابى مجدد قرار گرفت. در اين مطالعه سبك زندگى سالمندان به وسيله يرسشنامه سبك زندگى سالمندان كه توسط اسحاقى و

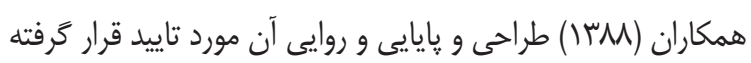
است (ضريب آلفاى كرونباخ برابر ول/•) مورد سنجش قرار كرفت. يرسشنامه مذكور داراى عثأ سوال به شرح زير مى باشد: ها سؤال در حيطه ييشگيرى، ه سؤال در حيطه فعاليت جسمى، ورزش، تفريح و

\begin{tabular}{|c|c|c|c|}
\hline آزمون آمارى & شاهد & مولتى مديا & كروه متغير \\
\hline $\begin{array}{l}\mathrm{T}=r / 1 \Lambda \\
\mathrm{p}=.1 .99\end{array}$ & SI/AV $(V / \Delta)$ & $\varepsilon \Delta / \Delta \vee(\xi / Q)$ & سن (سال) \\
\hline $\begin{array}{c}\mathrm{X} r=1 / \xi q \\
\mathrm{p}=\cdot / r\end{array}$ & $\begin{array}{l}\text { IT }(F \cdot \%) \\
\operatorname{IN}(\xi \cdot \%)\end{array}$ & $\begin{array}{l}\text { IV }(\Delta \xi / V \%) \\
I \Psi(\kappa / / \% \%)\end{array}$ & جنس \\
\hline $\begin{array}{c}\mathrm{X} r=s / \mathrm{V} \\
\mathrm{p}=\cdot 1 \cdot \wedge\end{array}$ & $\begin{array}{l}r(\%) \\
\aleph(\xi \cdot \%) \\
\Delta\left(\mathcal{N} / \kappa^{*}\right)\end{array}$ & $\begin{array}{l}r(\xi / V \%) \\
\backslash \Lambda(\xi . \%) \\
\Delta(\Lambda / F)\end{array}$ & وضعيت تاهل \\
\hline
\end{tabular}


جدول ب: مقايسه ميانكَين و انحراف معيار سبك زندگى (نمره كل و حيطه هاى تغذيه، فعاليت بدنى، بهداشت روان و مراقبت از خود) در كروه هاى مورد مطالعه

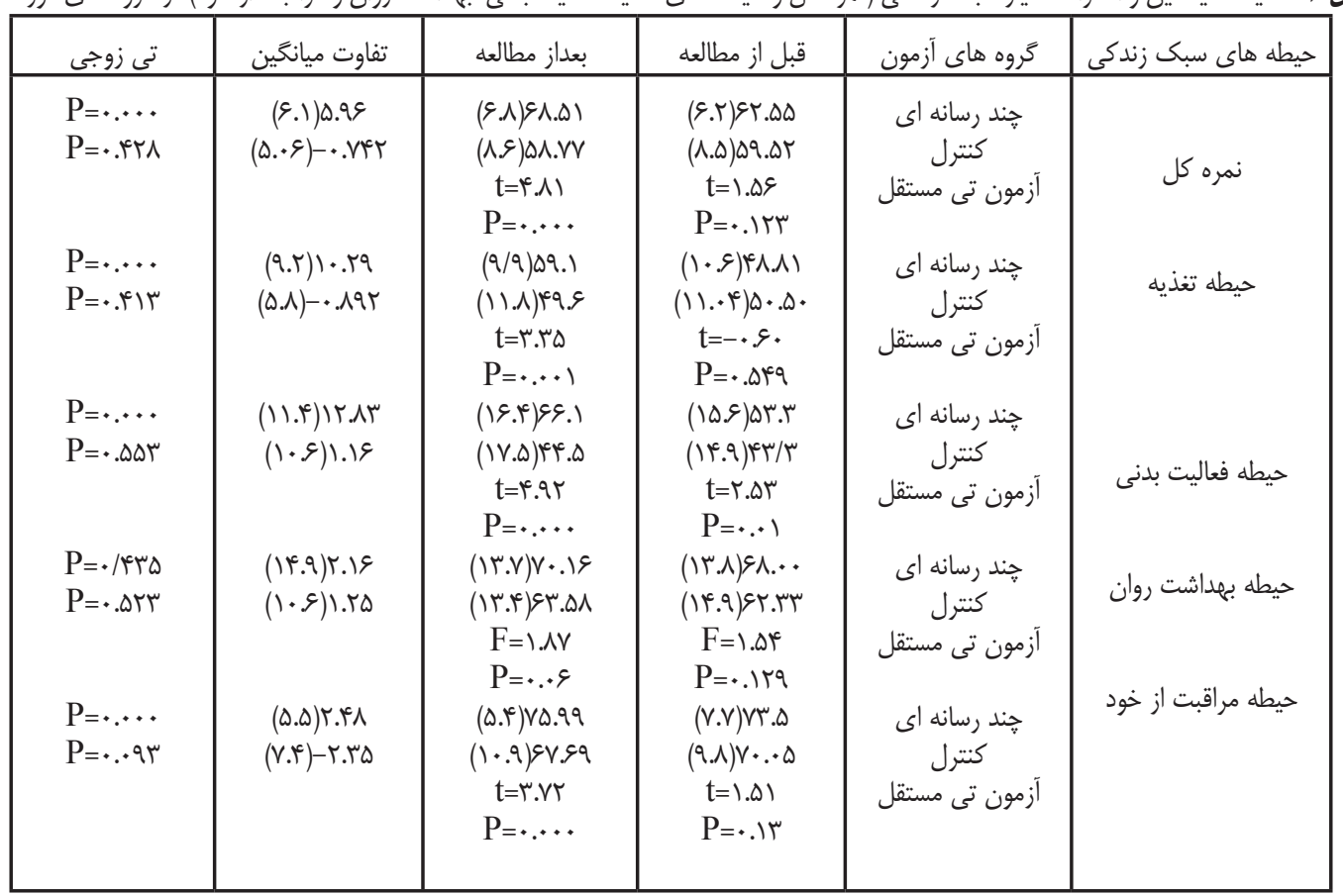

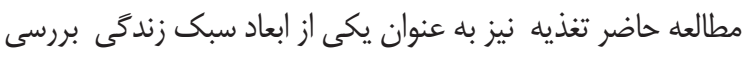

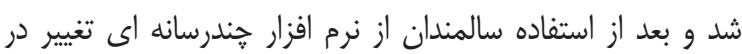
عادات تغذيه اى سالمندان مشاهده كرديد بطورى كه رفتارهاى تغذيه اى مطلوب در آنان نسبت به قبل از مداخله افزايش معنادار يافت، در

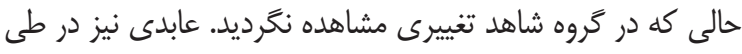
مطالعه اى به اين نتيجه رسيد كه آموزش به شيوه استفاده از فيله

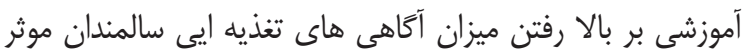

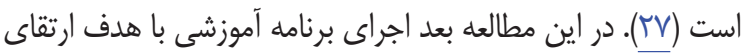

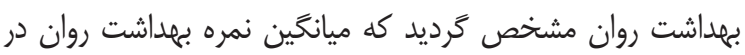
كروه مداخله بعد از اجراى برنامه آموزشى تغيير معنادار آمارى مشاهده نخَرديد. كه اين يافته بر خلاف يافته هاى مطالعه سبحانى و حاجى برون عزيزى (qr، (T) بود. كه اين نتيجه شايد به دليل بركذارى جلسات و كلاس هاى آموزشى روان شناسى متنوعى كه در سرا هاى محله بركَار مى شود و هجنين شركت بيشتر سالمندان در جلسات مذهبى باشد. و شايد نياز به بازنخَىى در محتواى مبحث بهداشت روان در نرم افزار هند رسانه اى براى تاثير بيشتر بر سلامتى روان سالمندان

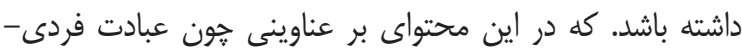
اجتماعى، شناخت علايق و استعدادهاى فردى، شركت در فعاليت هاى اجتماعى، مهارت هاى زندگى و ارتقاء حافظه تاكيد شده بود. در

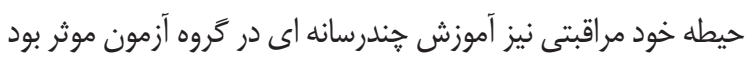
و تغيير معنادارى مشاهده شد. آموزش خودمراقبتى در سالمندان به حيه دليل شرايط ويزه

\section{به}

نتايج آزمون هاى آمارى تفاوت معنادارى در ميانخين نمره كلى سبك زندگى در دو گروه مداخله و شاهد را نشان داد كه نشان

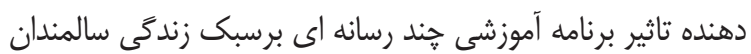

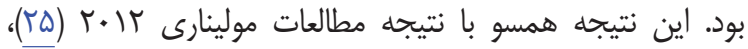

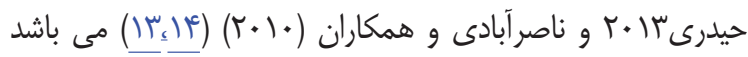
كه نتيجه نهايى افزايش اتخاذ خنين رفتارهايى، مطلوب تر شدن آنا

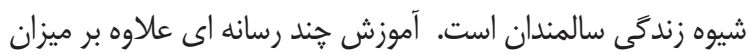

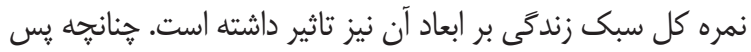

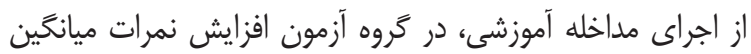
ابعاد سبك زندگى شامل: تغذيه، فعاليت بدنى، بهداشت روان و خود

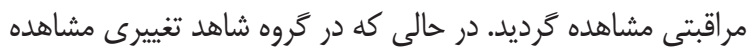
نشد كه بيانگر تاثير مثبت آموزشى هند رسانه اى بر ابعاد سبك هردي زندگى مى باشد. در خصوص فعاليت فيزيكى به عنوان يكى از ابعاد مهرم در مطالعات مربوط به سبك زندگى در مطالعه حاضر در دو گروه

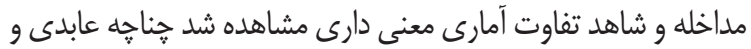
همكاران نيز در مطالعه شان افزايش فعاليت جسمى در زنان با فعاليت جسمى كم را يس از اجراى مداخله آموزشى مشاهده كردند (عَ)

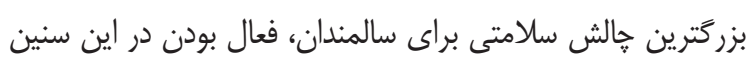

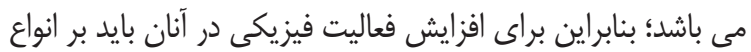
فعاليت فيزيكى تمركز كرد تا سالمندان از حالت ناتوانى در تحرى و و بى تحركى به سمت افزايش تحرى و فعاليت فيزيكى سوق دهيم. در 


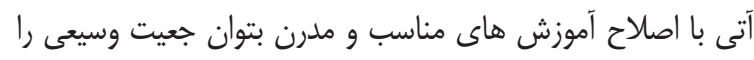

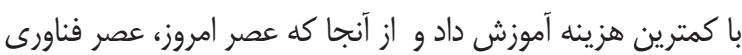

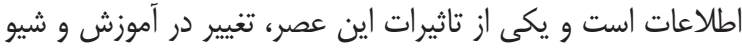

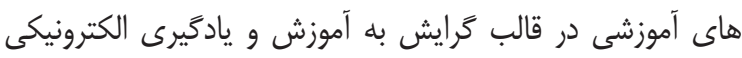

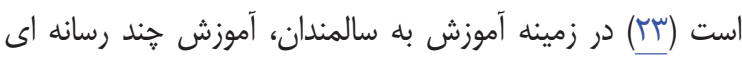

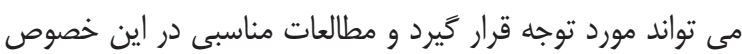

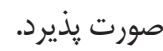

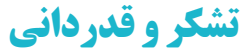

نويسندًان برخود لازم مى دانند مراتب سباس و قدردانى

خود را از كليه سالمندان شركت كننده در مطالعه و هميحنين مديران و مسئولان ذى ربط به دليل همكارى ابراز نمايند.

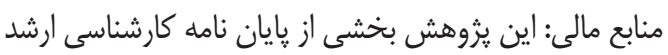
آموزش يرستارى در دانشكده يرستارى و مركز تحقيقات علوم رفتارى

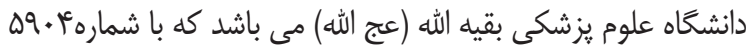
در كميته اخلاق دانشكاه علوم يزشكى بقيه الله (عج الله) مورد تاييدو

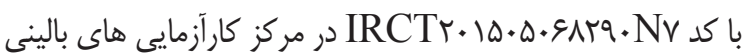

$$
\text { ايران به ثبت رسيده است. }
$$

\section{Refrences}

1. Khamse F, Movahedi M, Haji Amini Z, Ebadi A. [Healthy Lifestyle In Old Age]. Tehran: Parsa Mobtaker ; 2015. (Persian).

2. Wang C, Liao W, Kuo P, Yuan S-CK, Hsiao-Ling C, Hao-Chang L. The Chinese version of the facts on aging quiz scale: reliability and validity assessment. International Journal of Nursing Studies 2010; 47: 742 - 52.doi:10.1016/j. ijnurstu.2009.11.009.

3. Aalbersa T, M.A.E. Baarsa, Rikkerta MGMO Characteristics of effective Internet-mediated interventions to change lifestyle. Ageing Research Reviews. 2011;10:487-97. doi:10.1016/j. arr.2011. www.elsevier.com/locate/arr.

4. Fitzpatrick SL. Health Knowledge \& Health Behavior Outcomes in Adolescents with Elevated Blood Pressure. Electronic Theses and DissertationsOpen Access Dissertationshttp:// scholarlyrepositorymiamiedu/oa dissertations.2011.

5. Suraj S, Singh A. Study of sense of coherence health promoting behaviour in north Indian students. Indian J Med Res 2011;134:64552.icmr.nic.in/ijmr/2011/november.
است. يكى از مشكالت عملكردى خودمراقبتى، انجام آن در سالمندان است קراكه در دوران سالمندى، سازكارى شناختى و خوداتكايى كاهش مى يابد و شيوع بيماريهاى غير واگير افزايش مى يابد و

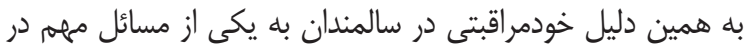

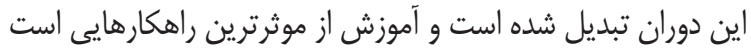

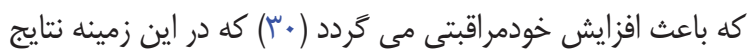
مطالعه قاسمى نيز بيانكر تاثير آموزش هاى خود مر اقبتى به سالمندان

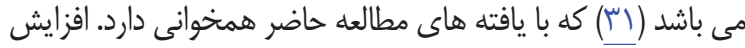
آكاهى سالمندان در مورد نيازهاى جسمى -روانى و روشهاى تغذيه سالم سبب ساز كارى مطلوب سالمندان با شر ايط سالمندى مى كَردان شايان ذكر است كه از جمله محدويت اين بزوهش مربوط به استفاده

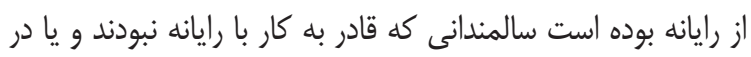
منزل زمينه استفده از رايانه را نداشتند از مطالعه كنار كذاشته شدند. به كارَّيرى برنامه هاى آموزشى مبتنى بر رويكرد سالمندى موفق در

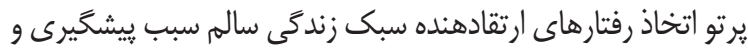
كاهش مشكلات مرتبط با سالمندى شده و به تبع آن كاهش هزينه

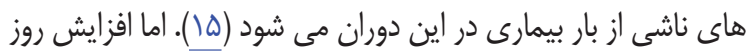
افزون جمعيت سالمندى اين ضرورت را ايجاب مى كند در سال هاى داى دائ

6. Ay S, Yanikkerem E, Calım SI, Yazıcı M.Healthpromoting Lifestyle Behaviour for Cancer Prevention of Turkish University Students. Asian Pacific Journal of Cancer Prevention.http// dx.doi.org/10.7314/APJCP.2012.13.5. 269.

7. Suri G, Gross JJ. Emotion regulation and successful aging. Trends in Cognitive Sciences 2012;16(8):PMID: 22739000 [PubMed indexed for MEDLINE]

8. Fiocco AJ, Scarcello S, Marzolini S, Chan A, Oh P, Proulx G, et al. The Effects of an Exercise and Lifestyle Intervention Program on Cardiovascular, Metabolic Factors and Cognitive Performance in Middle-Aged Adults with Type II Diabetes: A Pilot Study. Canadian Journal of Diabetes Can J Diabetes. 2013; 37: 214-9. Canadian Diabetes Association. available at SciVerse ScienceDirect. www.canadianjournal ofdiabetes. com. http://dx.doi.org/10.1016/j.jcjd. 2013.03.369.

9. Wittayapun Y, Tanasirirug V, B BB, Ekpanyaskul C. Factors affecting health-promoting behaviors in nursing students of faculty of nursing, Srinakharinwirot University, Thailand. Journal of Public Health. 2010; 40 (2): 215 - 25. http:// 
www. ph.mahidol.ac.th/journal.

10. Aihara Y, Minai J, Aoyama A, Shimanouchi S. Depressive symptoms and past lifestyle among Japanese elderly people.Community Mental Health Journal.2011: Apr; 47 (2): 93-186.

11. Tanaka H, Sasazawa Y, Suzuki S, Nakazawa M, Koyama $\mathrm{H}$.Health status and lifestyle factors as predictors of depression in middle-aged and elderly Japanese adults: a seven-year follow-up of the Komo-Ise cohort study.Bio Med Central, Japon .2011: 20 (1): 11-20.

12. Clark F, Jackson J, Carlson M, Chou CP, Cherry BJ, Jordan-Marsh M, et al. [Effectiveness of a lifestyle intervention in promoting the well-being of independently living older people: Results of the well elderly 2 randomised controlled trial]. Epidemiol Community Health. 2012; 66 (9): 782 -90 .

13. Heidari F, Kermanshahi SMK, Vanaki Z. The effect of a supportive health promotion program on the lifestyle of premenopause teachers. Feyz, Journal of Kashan University of Medical Sciences 2013; 17 (1): 14-24. http://feyz.hbi.ir [Persian].

14. Nasrabadi T, -Zadeh NG, Shahrjerdi A, Hamta A. The Effect of Education on Life Style among Patients Suffering from Ischemic Heart Disease. . J MazandaranUniv Med Sci. 2010; 20 (79): 729.http://jmums.mazums.ac.ir [Persian].

15. Taghdisi M, Estebsari F, Foroushani A, Ardebili H, Shojaeizadeh D, Dastoorpoor M. The educational program based on the successful aging approach on elders health-promoting behaviors: a clinical trial study. Razi Journal of Medical Sciences :2014Vol. 21, No. 125, OctNov

16. Mendoza-Núñez VM, Martínez-Maldonado ML, Correa-Muñoz E. Implementation of an active aging model in Mexico for prevention and control of chronic diseases in the elderly. BMC geriatrics. 2009; 9 (1):40.

17. 17.Movahedi M, Khaghanizade M, Khamseh F. Learning Effective Teaching Methods for SelfCare in Elderly. International Journal of Medical Reviews. 2015; 2 (1).

18. Safari, M; Shojaeizadeh, David, Mahmoud,Mahmoud, Hosseini, Seyed Reza. The effect of diet Food to lecture and film screening on knowledge. And the attitude of volunteer health workers. Quarterly Monitoring- 2010 .sal (first number) .p 63-71

19. Abedi Gh , Naghibi A , Alizadeh Khoei M, Faghrzadeh H, Sharifi F, Rezaei Rad M, et al. Efficacy of the two educational methods: Traditional and electronic techniques in training of nutritional aspect to healthy life style in elderly. Iranian Journal of Diabetes and Metabolism; 2013.13 (1) .9-20.

20. Rostami M, Baraz Pordanjani S, Farzianpour F, Rasekh A. Effect of Orem Self Care Model on ederies' quality of life in health care centers of Masjed Solaiman in 2007-2008. Journal of Arak University of Medical Sciences. 2009; 12 (2): 51-9 [Persian].

21. Beheshti M. Range zendegie kohansali. 1. Tehran: Neyestan; 2013. p. 15.

22. Movahedi M, Khamseh F, Ebadi A, Haji Amin Z, Navidian A. Assessment of the lifestyle of the elderly in Tehran. J Health Promot Manage 2016; 3: 519.

23. Najafi H, Shareable Content Object Refrence Model: Amodel for the production of electronic content for better learning. Educ Strategy Medsci.2017; 9 (5): 335-350

24. Eshaghi S, Farajzadegan Z, Babak A. Design and lifestyle questionnaire in elderly. Faslnameh of Isfahan Medical School. Winter 2009; the ninth year(first number): 91-9.

25. Molinari DL, Blad P, Martinez M. Seniors' Learning Preferences, Healthy Self-Care Practices and Computerized Education Implications. Online Journal of Rural Nursing and Health Care. 2012; 5 (1): 48-58.

26. Abedi P,Lee M, Kandiah M, YassinZ,Shojaeezade D, Hosseini M, et al. Lifestyle Change Using the Health Belief Model to Improve Cardiovascular Risk Factors among Postmenopausal Iranian Women. J Health System Res. 2011; 7 (1):12737. http://congress. tbzmed. ac.ir [Persian].

27. Abedi Gh, Naghibi A, Alizadeh Khoei M, Faghrzadeh H, Sharifi F, Rezaei Rad M , et al. Efficacy of the two educational methods: Traditional and electronic techniques in training of nutritional aspect to healthy life style in elderly. Iranian Journal of Diabetes and Metabolism; 2013.13 (1) .9-20.

28. Sobhani A, Shahnazi H, Mostafavi F; The Efficiency of Theory-Based Education on 
Mental Health Subscales in Elders: Application of Theory of Planned Behavior. Journal of Health Education and Health Promotion, 2019; 6 (4): 367 - 375.

29. Hajiazizi A, Bahmani, Mahdi N, Manzari Tavakoli V, Barshan A; Effectiveness of Group Logotherapy on Death Anxiety and Life Expectancy of the Elderly Living in Boarding Houses in Kerman Salmand: Iranian Journal of Ageing 2017, 12 (2): 220 - 231.

30. Weinger K, Beverly EA, Smaldone A. Diabetes self-care and the older adult. Western Journal of Nursing Research. 2014; 36 (9): 1272 - 98.

31. Ghasemi M, Hosseini H, Sabouhi F; The effect of peer group training on self - care of elderly with diabetes mellitus. Journal of Clinical Nursing and Midwifery 2017; 6 (3): 33 - 43. 